\title{
Damping techniques for grid-connected converters with LCL filter: an overview
}

\section{Técnicas de amortecimento para conversores conectados à rede elétrica com filtro LCL: uma revisão}

\author{
Arthur de Abreu Romão ${ }^{1}$; Newton da Silva ${ }^{2}$
}

\begin{abstract}
Distributed generation systems, based on renewable energy sources, are typically connected to the main grid by a voltage-source inverter with a low-pass filter. The need for improved efficiency led to the use of third order low-pass filters, such as the LCL configuration, which has resonant behavior. In order to meet energy quality requirements and ensure the systems stability it is necessary to suppress the LCL filters resonance through damping techniques. Therefore, this paper presents an overview of some damping strategies found in literature and its design procedure, applied to a simulated single-phase grid-tied inverter. The comparison of each presented damping methodology characteristics is described, with analysis of advantages and drawbacks for each case.
\end{abstract}

Keywords: Energy quality. Digital filters. Current control. Renewable sources. Power electronics.

\section{Resumo}

Sistemas de geração distribuída, baseados em fontes de energia renováveis, são tipicamente conectados a rede elétrica através de um inversor de frequência com um filtro passa-baixa. A necessidade de uma maior eficiência levou ao uso de filtros passa-baixa de terceira ordem, como a configuração LCL, que possui um comportamento ressonante. Para que seja possível atender as exigências para qualidade de energia e garantir a estabilidade do sistema é necessário suprimir a ressonância do filtro LCL através de técnicas de amortecimento. Portanto, este artigo apresenta um resumo de algumas estratégias de amortecimento encontradas na literatura e considerações de projeto, aplicado a um inversor monofásico conectado à rede elétrica simulado. A comparação das características de cada metodologia de amortecimento apresentada é descrita, com a análise de vantagens e desvantagens para cada caso.

Palavras-chave: Qualidade de energia. Filtros digitais. Controle de corrente. Fontes renováveis. Eletrônica de potência.

\footnotetext{
${ }^{1}$ Me., Degree student, Dept. Electrical Engineering, UEL, Londrina, PR, Brazil, E-mail: arthur.romao@ outlook.com

${ }^{2}$ Prof. Dr., Dept. Electrical Engineering, UEL, Londrina, PR, Brazil, E-mail: newton.silva@uel.br
} 


\section{Introduction}

Renewable energy sources, such as photovoltaic (PV) and wind farms, constitute an important part of distributed generation (DG) systems tied to the main grid, helping supply the growing global energy demand and diversify the energy matrix, consequently mitigating the environmental impacts caused by fossil fuel electric power generation (BARBOSA et al., 2016).

DG systems are electric power generation within the distribution network or installed alongside the consumer unit (YADAV; SRIVASTAVA, 2014). For this reason, the DG system is connected to the main grid by a single or three-phase voltage-source inverter (VSI) (LISTON et al., 2018). Applications with low installed power $(<10 \mathrm{~kW})$, such as residential PV generation, the VSI are typically a single-phase connected at low voltage $(110-220 \mathrm{~V})$ (CALZO et al., 2012).

The VSI connection to the main grid must comply with requirements that ensures the safety and energy quality provided by the DG system, hence the VSI is connected to the grid by a low-pass filter which reduces the switching harmonics (KRAEMER et al., 2018).

In early systems the low-pass filter used was a pure inductive, first order $\mathrm{L}$ filter. It presented the advantage of simplicity in implementation and control, however, the inductance value has to be high in order to meet the energy quality requirements, resulting in less efficiency, larger voltage drop and bigger physical dimensions (CHA; VU, 2010).

Consequently, the increasing necessity for more efficient and smaller systems led to the adoption of higher order filters, such as the third order inductive-capacitiveinductive (LCL) filter (YAGNIK; SOLANKI, 2017). Although it presents an improvement in energy losses and higher frequency attenuation, the third order nature of this configuration increases the complexity in implementation and control (GOMES; CUPERTINO; PEREIRA, 2018). Mainly, the resonant behavior of the LCL filter needs to be suppressed in order to ensure stability and the required energy quality (PARKER; MCGRATH; HOLMES, 2014).

For the suppression of resonance in LCL filter, different damping techniques are presented throughout the literature, each presenting its own particular characteristics, advantages and disadvantages. In this context, this paper aims to present a critic overview of the more widely found damping strategies. The different aspects of resonance suppression techniques are compared through the analysis of mathematical model, implementation methodology and computational simulation in MATLAB ${ }^{\circledR}$.

This paper is organized in seven sections. Beginning with a System description section, where it describes the structure used for obtaining the simulation results. Followed by the LCL filter model section, presenting the filters transfer function regarding grid-side current as the output signal and the duty cycle as the input signal, and through the analysis of the filters transfer function the resonant aspect is also discussed.

The section Passive damping (PD) describes some of the methods that achieve the resonance suppression due to application of a resistive element into the filter structure, introducing energy losses that, consequently, leads to a damped response (PEÑA-ALZOLA et al., 2013a). The following section presents the Active damping (AD), developed as a mean for achieving resonance suppression through the current control structure, and, therefore, reaching higher efficiency by dismissing the necessity of resistive elements (GOMES; CUPERTINO; PEREIRA, 2018).

In the Simulation results section the damping strategies are simulated in MATLAB ${ }^{\circledR}$ and compared, in order to show how each method affects the systems response. Finally, the last section brings the conclusions.

\section{System description}

The control structure and LCL filter used for the damping techniques analysis is shown in Figure 1. It contains a single-phase VSI connected to the main grid by an LCL filter, with the VSI being powered by a DC bus, and a resistive local load $\left(\mathrm{R}_{\mathrm{L}}\right)$ connected to the point of common coupling (PCC).

The current reference signal is generated by multiplying a unit value sinusoidal signal, which is in sync with the grid voltage signal, a result from the phase-locked-loop (PLL) algorithm, with a constant value $\left(i_{p k}\right)$ that represents the reference current peak value.

The current control structure, Figure 1, uses the proportional-resonant (PR) control with harmonic compensation (HC) scheme, with grid current feedback. The proportional-resonant controller $(P R(s))$ and $\mathrm{HC}$ $\left(R_{h}(s)\right)$ transfer functions are presented in equations (1) and (2), respectively, given by

$$
\begin{gathered}
P R(s)=K_{p}+K_{r} \frac{s}{s^{2}+\omega_{g}^{2}}, \\
R_{h}(s)=\sum_{h=3,5,7 \ldots} \frac{K_{r h} s}{s^{2}+\left(h \omega_{g}\right)^{2}},
\end{gathered}
$$


Figure 1 - System structure, with PR control and LCL filter.

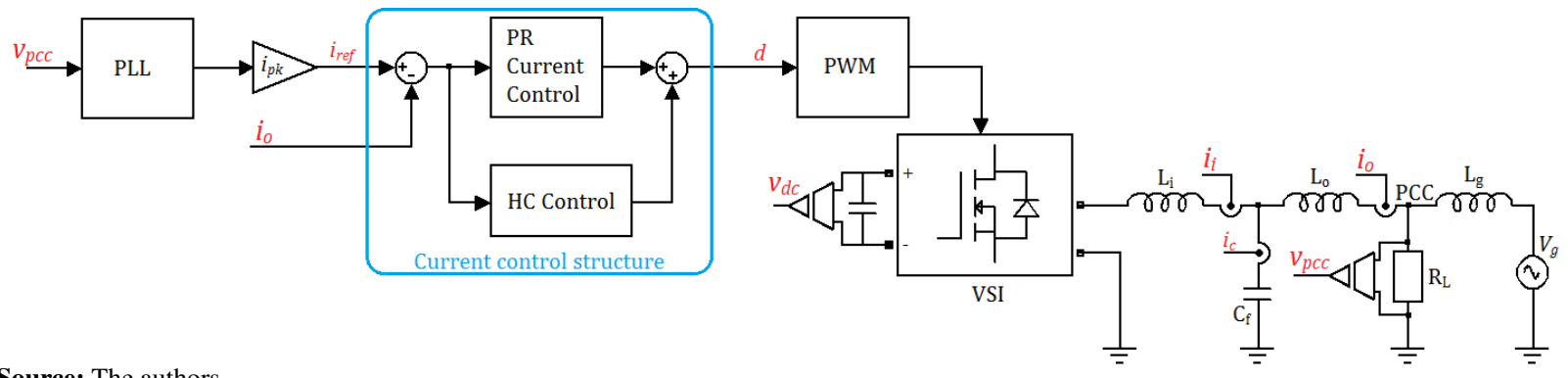

Source: The authors.

where $\omega_{g}$ is the main grid frequency in $\mathrm{rad} / \mathrm{s}, h$ the order of harmonic component and $K_{p}, K_{r}$ and $K_{r h}$ the control gains (YUAN et al., 2002).

The resonant controller applied in the current control is widely used in grid tied systems due to the ability to eliminate the steady-state error between the controlled signal and its sinusoidal reference (KRAEMER et al., 2018). In the current control topology, presented in Figure 1, the difference between reference signal and acquired current signal is compensated by a proportional gain and resonant controllers, tuned in the mains frequency and in some of its harmonics that is desired to reject.

The resulting signal is applied to a PWM generator that drives the VSI, producing the desired current signal in the grid-side inductor.

The VSI, PWM block and LCL filter can also be represented in the form of block diagram, illustrated in Figure 2, without the connection of a local load in the PCC. This representation is particularly useful for modeling the AD methods, as shown in the section Active damping.

Figure 2 - VSI and LCL filter represented in the form of block diagram.

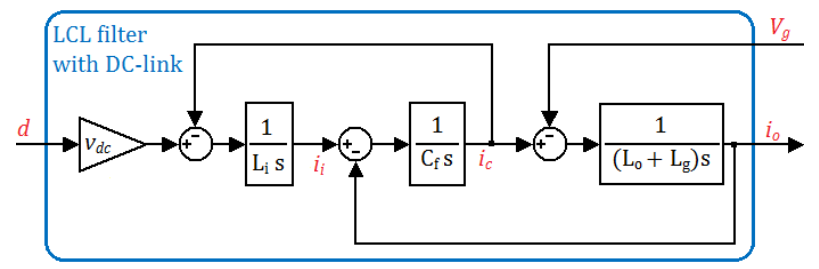

Source: The authors.

The filter components are designed as described by Peña-Alzola et al. (2014), resulting in the system parameters presented in Table 1.

In order to be possible to implement the resonant controllers in a digital signal processor (DSP) the discretization by impulse invariant method is recommended, as described by (YEPES et al., 2010), and presented in
Table 1 - System parameters.

\begin{tabular}{ccc}
\hline Parameter & Symbol & Value \\
\hline Inverter side LCL filter inductance & $L_{i}$ & $1.4 \mathrm{mH}$ \\
Grid side LCL filter inductance & $L_{o}$ & $1.4 \mathrm{mH}$ \\
LCL filter capacitance & $C_{f}$ & $4 \mu \mathrm{F}$ \\
Strong grid equivalent inductance & $L_{g}$ & $0 \mathrm{mH}$ \\
Weak grid equivalent inductance & $L_{g}$ & $1 \mathrm{mH}$ \\
Local load resistance & $R_{L}$ & $160 \Omega$ \\
Effective grid voltage & $V_{g}$ & $115 \mathrm{~V}$ \\
DC bus voltage & $v_{d c}$ & $180 \mathrm{~V}$ \\
Grid frequency & $f_{g}$ & $60 \mathrm{~Hz}$ \\
Switching frequency & $f_{s}$ & $14400 \mathrm{~Hz}$ \\
\hline
\end{tabular}

Source: The authors.

equation (3), where the $z$-domain resonant filter shows the closest response to the s-domain continuous counterpart

$R(z)=K_{r} T_{s} \frac{\cos \left(h \omega_{g} N T_{s}\right)-\cos \left(h \omega_{g}(N-1) T_{s}\right) z^{-1}}{1-2 \cos \left(h \omega_{g} T_{s}\right) z^{-1}+z^{-2}}$,

where $T_{s}$ is the sampling period and $N$ represents the number of samples to be compensated, in most cases $N=2$ compensates the measurement and control delay (YEPES et al., 2010). The parameter $h$ indicates the harmonic order, with $h=1$ being the resonant control for the mains frequency.

The resonant filter in $z$-domain presented in equation (3) is implemented in the Direct Form II (KAURANIEMI et al., 1998), as depicted in Figure 3.

The elements for Direct Form II shown in Figure 3 are defined by comparing equation (3) with equation (4), where

$$
H(z)=\frac{b_{0}+b_{1} z^{-1}+b_{2} z^{-2}}{1+a_{1} z^{-1}+a_{2} z^{-2}} .
$$

For each damping technique the proportional and resonant gains are designed through root locus, selecting the closed loop poles that provide an stable response with low steady state-error for all cases. 
Figure 3 - Direct Form II filter implementation.

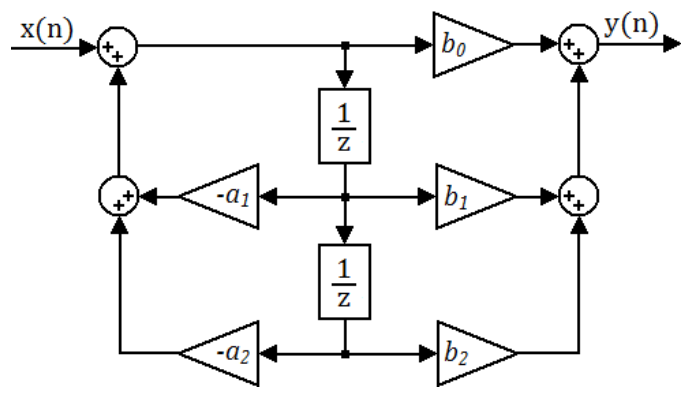

Source: The authors.

\section{LCL filter model}

The VSI and LCL filter can be understood, in a simplified manner, as the circuit shown in Figure 4. Considering all ideal elements.

Figure 4 - Equivalent circuit of the grid-tied VSI with LCL filter.

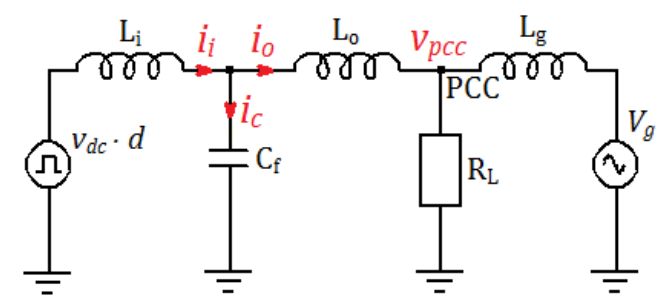

Source: The authors.

In order to obtain the filter transfer function for control analysis, regarding the duty cycle $(d)$ as the input signal and grid-side current $\left(i_{o}\right)$ as the output signal, the DC bus voltage $\left(v_{d c}\right)$ is considered constant and the local load $\left(R_{L}\right)$ is approximated to an infinite resistance. By solving the circuit disregarding the grid voltage $\left(V_{g}=0\right)$ the LCL filter transfer function $G_{p}(s)$, which also represents the systems plant, presented in

$$
G_{p}(s)=\frac{i_{o}(s)}{d(s)}=\frac{\frac{v_{d c}}{L_{i} C_{f}\left(L_{o}+L_{g}\right)}}{s^{3}+\frac{L_{i}+L_{o}+L_{g}}{L_{i} C_{f}\left(L_{o}+L_{g}\right)} s},
$$

is obtained.

The equation (5) shows three poles: one in $s=0$ while the two remaining results in the resonance frequency value $\left(\omega_{r}\right)$, given by

$$
\omega_{r}=\sqrt{\frac{L_{i}+L_{o}+L_{g}}{L_{i} C_{f}\left(L_{o}+L_{g}\right)}} .
$$

The equation (6) describes the frequency where transfer function, see equation (5), approaches an infinite gain, therefore, as a result of the resonant behavior, the VSI with undamped LCL filter may present high total harmonic distortion (THD) and even lead to an unstable system (GUO; WU; GU, 2010).

To avoid resonance, a damping factor can be introduced in the LCL filter transfer function denominator through application of resistive elements in association with the LCL filter components, this being known as passive damping (PEÑA-ALZOLA et al., 2013a). It is also possible to add the damping factor through the feedback of some filters signals, such as inductor current (LISTON et al., 2018) or capacitor voltage (XIN et al., 2016), in order to emulate the presence of a resistive element, this damping method is known as virtual resistor AD.

Other methodology for $\mathrm{AD}$ is through the use of a notch filter in series with the current controller (PEÑAALZOLA et al., 2013b), placing the notch filter zeros at the same frequency as the poles responsible for the LCL filter resonance.

Those damping techniques are discussed in details in the following sections.

\section{Passive damping (PD)}

For obtaining a damping factor through passive techniques it is inevitable the dissipation of energy in the resistive element, therefore, the methods of PD focuses not only in promoting the filter damping, but also in achieving the best possible efficiency and frequency response. The resistor position within the filter, and the association with additional reactive elements, can help reduce power losses and improve the frequency response (PEÑA-ALZOLA et al., 2013a).

This section discusses some of the most used types of passive damping and its characteristics.

\section{Series capacitor resistor}

As presented by Liserre, Blaabjerg and Hansen (2005), the placement of a resistor in series with the filter capacitor the resultant equivalent circuit is as presented in Figure 5.

Similarly to the case with LCL filter without damping, the transfer function for the circuit presented in Figure 5 is obtained through Kirchoffs law, with $v_{d c}$ being constant, considering only the action of duty-cycle input $(d)$, therefore $V_{g}=0$, with grid-side current as the output signal. The load is considered as an infinite impedance. 
Figure 5 - Equivalent circuit of the LCL filter with series capacitor resistor PD.

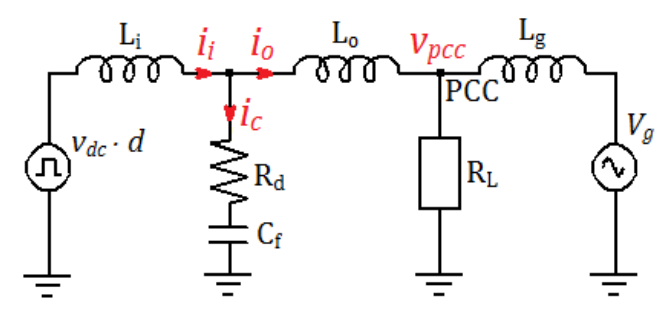

Source: The authors.

These considerations results in the transfer function $G_{p d s}$ presented in equation (7),

$$
G_{p d s}(s)=\frac{i_{o}(s)}{d(s)}=\frac{\frac{C_{f} R_{d} s+1}{L_{i} C_{f}\left(L_{o}+L_{g}\right)} v_{d c}}{s^{3}+R_{d} \frac{L_{i}+L_{o}+L_{g}}{L_{i}\left(L_{o}+L_{g}\right)} s^{2}+\omega_{r}^{2} s} .
$$

The inspection of equation (7) shows the presence of a zero, which causes a effect in the higher frequency response of the filter, reducing its attenuation capabilities.

By comparing the denominator of transfer function, in equation (7), with a general second-order system (BASSO, 2016), presented in equation (8),

$$
H(s)=\frac{K \omega_{r}^{2}}{s^{2}+2 \zeta \omega_{r} s+\omega_{r}^{2}},
$$

it is possible to notice the presence of a damping factor $(\zeta)$, therefore, the damping resistor $R_{d}$ placed in series with the capacitor help suppress the resonant effect, placing the poles in an stable region and reducing the harmonic distortion caused by the resonance.

With further comparison between equations (7) and (8), the damping factor for this topology is obtained, presented in equation (9),

$$
\zeta_{r c s}=\frac{C_{f} R_{d} \omega_{r}}{2}
$$

In order to limit losses the damping factor should be as $\zeta<<1$ (GOMES; CUPERTINO; PEREIRA, 2018). For design reference, Peña-Alzola et al. (2013a) suggests that the $R_{d}$ value should be limited by the capacitor impedance at the switching frequency, resulting in the $R_{d, \max }$ value presented in equation (10),

$$
R_{d, \max }=\frac{1}{2 \pi f_{s} C_{f}} .
$$

Furthermore, it is suggested by Liserre, Blaabjerg and Hansen (2005) that, in order to obtain good compromise between filter attenuation, stability and power losses, the damping resistance should be equal to one third of the capacitor impedance at the resonant frequency, as presented in equation (11),

$$
R_{d, r c s}=\frac{1}{3 \omega_{r} C_{f}}
$$

Using the equation (11), for the filter described in the Table 1 , it results in a resistor $R_{d}=5 \Omega$, giving a damping factor of $\zeta \approx 0.17$.

The frequency response comparison with the undamped filter is presented in the Bode diagram in Figure 6, made in MATLAB ${ }^{\circledR}$, based on the transfer functions in equations (5) and (7), for the case without damping, and for the case with series capacitor resistor PD, respectively. The Table 1 gives the parameters values.

Figure 6 - Bode diagram: frequency response comparison for filter without damping and with series capacitor resistor PD.

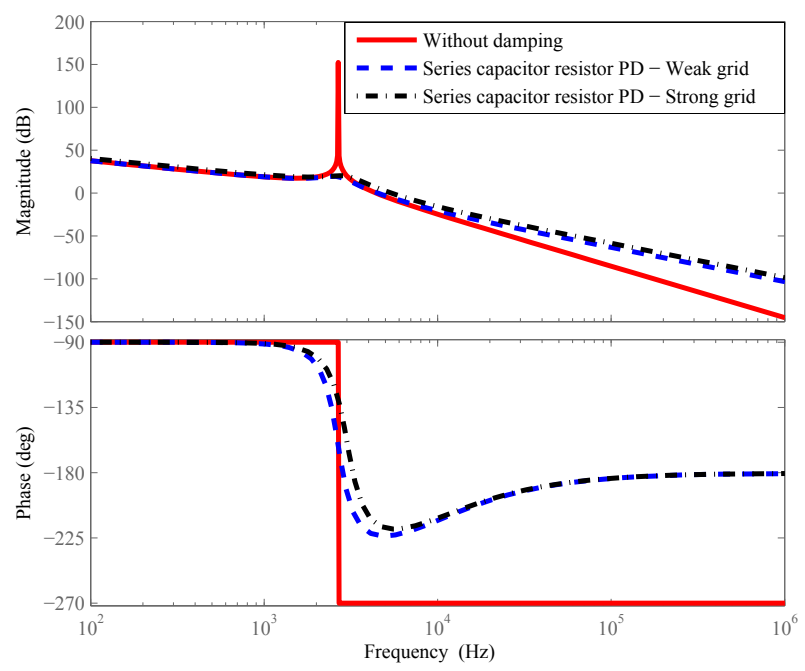

Source: The authors.

The Figure 6 demonstrates that the series capacitor resistor PD is capable of suppressing the resonant behavior, regardless of equivalent grid inductance, however, it also compromise the filter attenuation for the higher frequencies.

In order to obtain the proportional gain $K_{p}$, the root locus plot, for the system presented in Figure 1, is shown in Figure 7, considering the parameters described in Table 1.

As the resonant control gains $K_{r}$ and $K_{r h}$ does not influence stability it is set to zero (LIU et al., 2020), however its value must be enough to provide minimum steady state error and harmonic rejection. The design for the resonant gains is discussed in the section Simulation Results. Thus, the value of $K_{p}=0.02$ is chosen as it guarantees stable closed-loop poles. 
Figure 7 - Root locus for $K_{p}$ design with series capacitor resistor PD.

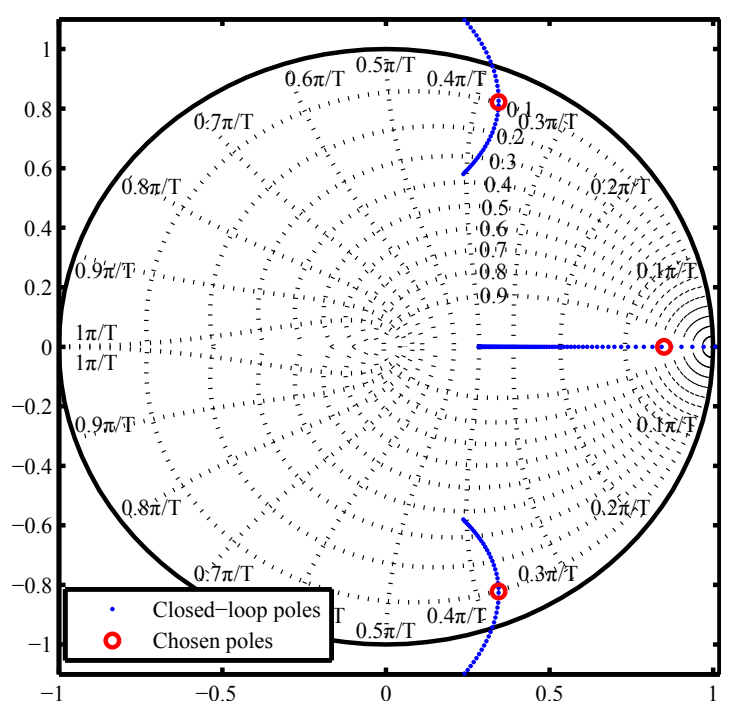

Source: The authors.

\section{Parallel inductor resistor}

For obtaining a practical PD with a parallel configuration the resistor should be placed alongside the filter inductors, in order to reduce power losses. According to Guo, Wu and $\mathrm{Gu}$ (2010), the best dynamic performance and high frequencies attenuation is achieved by placing the damping resistor in parallel with the grid-side inductor, as shown in Figure 8.

Figure 8 - Equivalent circuit of the LCL filter with parallel inductor resistor PD

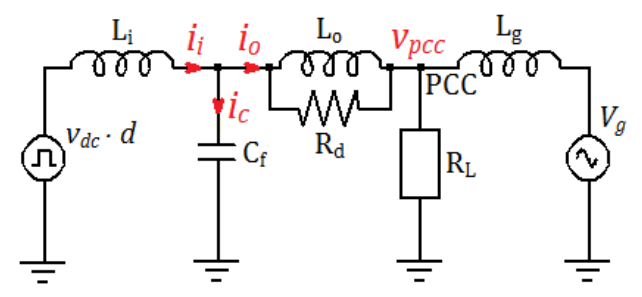

Source: The authors.

Through the same methodology used for obtaining the transfer function for the series capacitor resistor PD, showed in equation (7), the model for parallel PD can also be deducted.

Although in this case, since the presence of the grid equivalent inductance elevates the systems order in one degree, it is considered a strong grid condition, thus, the equivalent grid inductance is approximated to zero. Consequently, the transfer function that describes the circuit, depicted in Figure 8, at the described conditions, is presented in equation (12),

$$
G_{p d p}(s)=\frac{i_{o}(s)}{d(s)}=\frac{\frac{L_{o} s+1}{L_{i} C_{f} L_{o}} v_{d c}}{s^{3}+\frac{1}{C_{f} R_{d}} s^{2}+\omega_{r}^{2} s} .
$$

Due to the presence of a zero in the transfer function (12), it is expected that the resistor in parallel with the grid-side inductor also affects the high frequency attenuation of the filter, at strong grid conditions.

By comparing equations (12) and (8) it is possible to obtain the damping factor for this kind of PD, presented in equation (13),

$$
\zeta_{r l p}=\frac{1}{2 \omega_{r} C_{f} R_{d}} .
$$

In contrast with the series capacitor PD, the damping factor for this case is inversely proportional to the resistor value, therefore, in order to reduce power loss, higher values for $R_{d}$ should be employed.

The damping resistor design proposed by Guo, $\mathrm{Wu}$ and $\mathrm{Gu}$ (2010) uses root-locus analysis. In this paper, for frequency response comparison, the resistor is obtained using an equivalent damping factor as the series capacitor resistor $\mathrm{PD}$, therefore, using $\zeta \approx 0.17$ results in $R_{d}=45 \Omega$.

The frequency response for the filter with parallel inductor resistor PD, at weak and strong grid conditions, in relation to the undamped LCL filter, is presented in Figure 9, obtained through MATLAB ${ }^{\circledR}$. It considers the system described in Table 1.

Figure 9 - Bode diagram: frequency response comparison for filter without damping and with parallel inductor resistor PD.

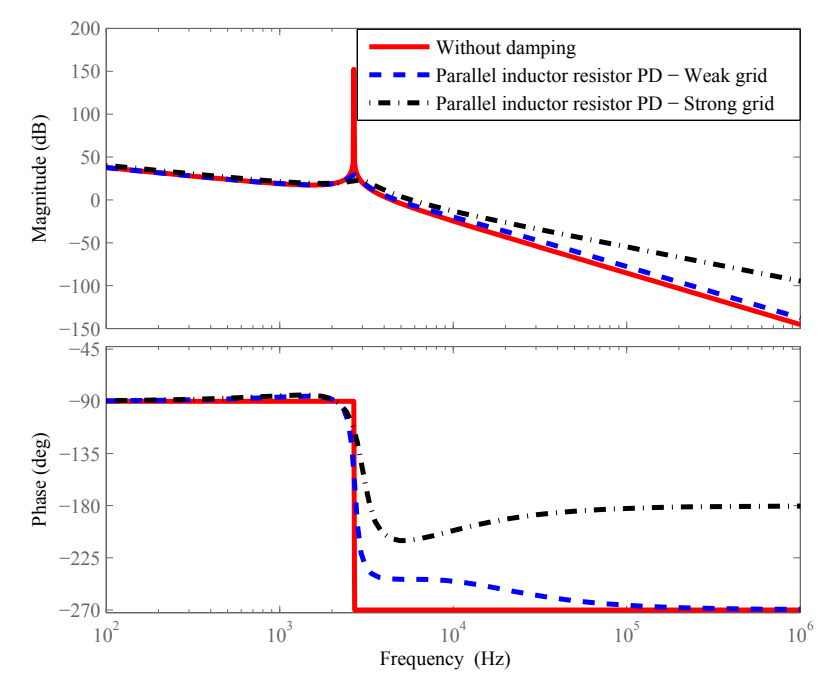

Source: The authors. 
Figure 9 shows the damping capability of the parallel inductor resistor PD, although it also affects the high frequency attenuation of the LCL filter, although, the impact of this PD methodology in the filter response, at weak grid condition, is smaller if compared to the series capacitor resistor PD approach. For strong grid both methods presents the same characteristics, behaving as an approximation of a second order low-pass filter.

For the parallel inductor resistor PD the design of proportional gain $K_{p}$ is done by the root locus plot shown in Figure 10, in the same way as described for the series capacitor resistor. The chosen value for the proportional gain is $K_{p}=0.02$, as it also provides an stable response for the parallel inductor resistor PD.

Figure 10 - Root locus for $K_{p}$ design with parallel inductor resistor PD.

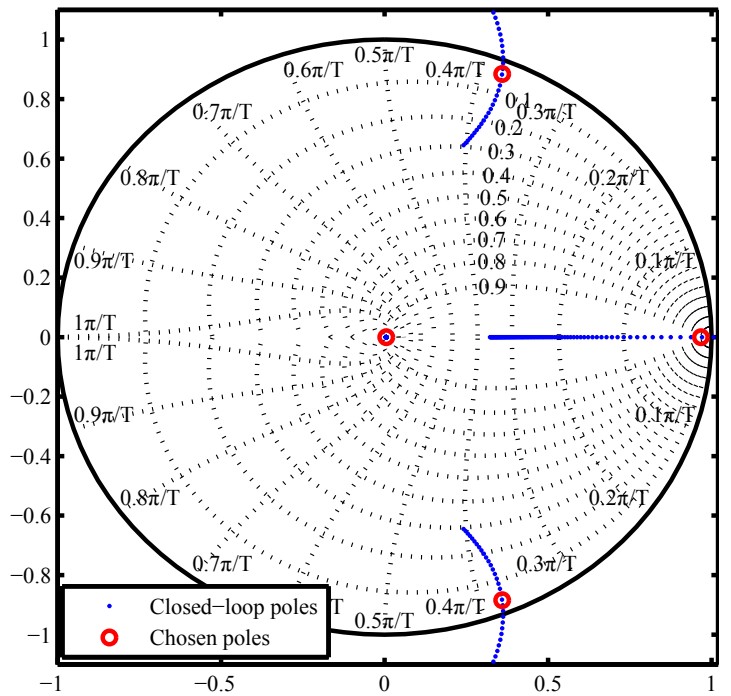

Source: The authors.

\section{Complex PD}

In an attempt to further improve the power losses in PD methods, as it is an important issue for medium and high power applications (GOMES; CUPERTINO; PEREIRA, 2018), some authors proposes the use of complex PD techniques.

The use of complex PD improves the efficiency by adding reactive elements in association with the damping resistor and different topologies were suggested, such as: an inductor in parallel with damping resistor in the capacitor branch (WANG et al., 2003), split capacitor method (CHANNEGOWDA; JOHN et al., 2010), and others with higher order and complexity (BALASUBRAMANIAN; JOHN, 2013; ROCKHILL et al., 2011; KANG et al., 2013).
Due to its simplicity, good performance and frequency response (BERES et al., 2016), the split capacitor method is widely found throughout the literature, consequently, this method is chosen to be discussed further in this paper.

The equivalent circuit for the split capacitor complex PD is depicted in Figure 11, notice that for this case the capacitor is divided, as a result $C_{f d}$ has a different value from the original $C_{f}$.

Figure 11 - Equivalent circuit of the LCL filter with split capacitor complex PD

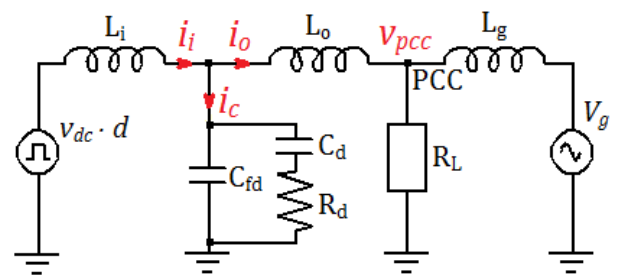

Source: The authors.

The configuration presented in Figure 11, due to the presence of two capacitors, results in a system of fourth order, as shown by the transfer function presented in equation (14),

$$
\begin{aligned}
G_{p d c}(s)= & \frac{i_{o}(s)}{d(s)} \\
= & \frac{\frac{1}{L_{i} C_{f d}\left(L_{o}+L_{g}\right)}\left(s+\frac{1}{C_{d} R_{d}}\right) v_{d c}}{s^{4}+\frac{C_{f d}+C_{d}}{C_{f d} C_{d} R_{d}} s^{3}+\omega_{r}^{2} s^{2}+\frac{\omega_{r}^{2}}{C_{d} R_{d}} s} .
\end{aligned}
$$

Although the equation (14) shows the presence of a zero, the additional pole introduced by the RC damping branch should compensate the effects in high frequency attenuation (BERES et al., 2016).

Accordingly to Channegowda and John (2010), the design for the capacitor $C_{d}$ should be done in such manner that the frequency response of the LCL filter is unchanged, thus the total filter capacitance needs to be kept the same as the original $C_{f}$, as showed by equation (15),

$$
C_{f}=C_{f d}+C_{d}
$$

Also, a ratio between $C_{f d}$ and $C_{d}$, represented by $\alpha$ in equation (16),

$$
C_{d}=\alpha C_{f d},
$$

is used in order to design the capacitors values.

It is stated by Channegowda and John (2010) that the selection of $\alpha$ is a trade-off between effective damping and power loss in the shunt branch, concluding that the best 
choice is setting $\alpha=1$, resulting in the same capacitance value for both capacitors.

The design for damping resistor $R_{d}$ uses the equation (17) (CHANNEGOWDA; JOHN et al., 2010), given by

$$
R_{d}=\sqrt{\frac{L_{i}+L_{o}}{C_{f d}+C_{d}}}=\sqrt{\frac{L_{i}+L_{o}}{C_{f}}} .
$$

Using the design guidelines provided by Channegowda and John (2010) the obtained filter capacitors are: $C_{f d}=$ $C_{d}=2 \mu F$. The resistor $R_{d}=26 \Omega$.

The frequency response for the undamped filter in comparison with the split capacitor complex PD is presented in Figure 12, obtained through MATLAB ${ }^{\circledR}$, showing its ability to successfully suppress the resonance.

Figure 12 - Bode diagram: frequency response comparison for filter without damping and with split capacitor complex PD.

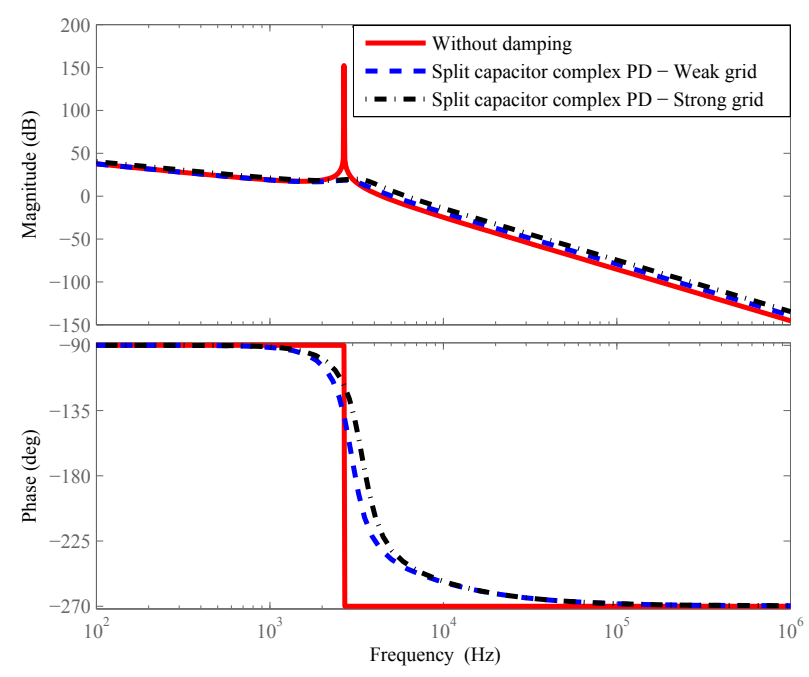

Source: The authors.

It is noticeable from Figure 12 that the LCL filter response with split capacitor complex PD has a slight difference from its undamped counterpart, however, it shows an improvement from the series capacitor resistor in the higher frequencies, and presents a better robustness to the grid equivalent inductance variation if compared to the parallel inductor resistor. Furthermore, the complex PD scheme provides lower power losses than the pure resistive alternatives (PEÑA-ALZOLA et al., 2013a).

In a similar manner as described for the series capacitor resistor and parallel inductor resistor PD, the proportional gain $K_{p}$ for the complex PD case is done through the root locus analysis, presented in Figure 13. The gain of $K_{p}=0.02$ also provides an stable response, thus being the chosen value.
Figure 13 - Root locus for $K_{p}$ design with complex PD.

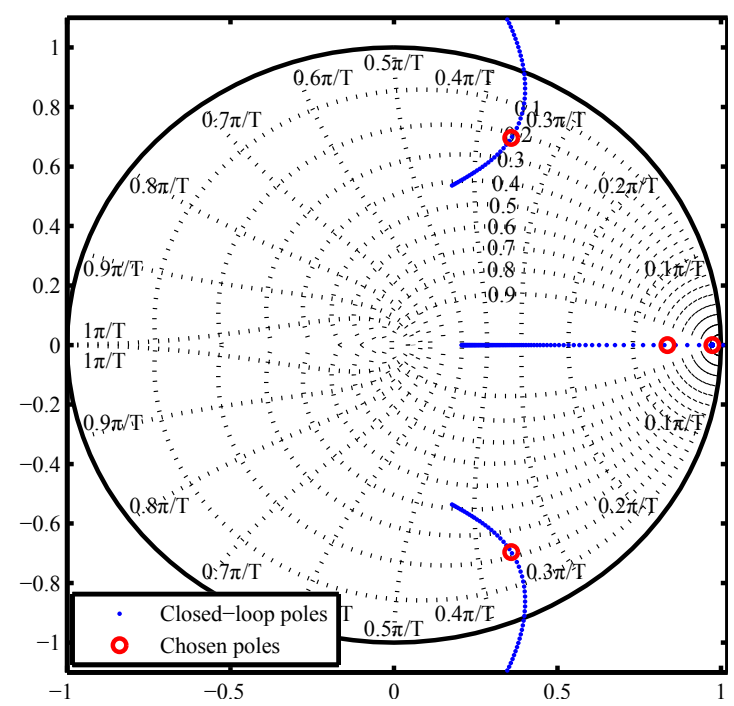

Source: The authors.

\section{Active damping (AD)}

Although the complex PD can improve some drawbacks of PD, such as the lower attenuation in higher frequencies and the energy dissipation in the damping resistor, it does not fully solve these issues. In order to further improve energy efficiency of the resonance suppression in LCL filters the active damping methods were proposed (GOMES; CUPERTINO; PEREIRA, 2018).

The AD can be grouped into two categories, the notch filter and virtual resistor, each one is discussed in this section.

\section{Notch filter}

The notch filter AD is implemented by placing the filter in series with the current controller, immediately before the LCL filter, as presented in Figure 14, where $N(s)$ represents the notch filter and $v_{d c}$ the VSI DC-link. This strategy does not need any additional feedback, consequently it has the advantage of implementation simplicity (DANNEHL; LISERRE; FUCHS, 2011).

Figure 14 - VSI and LCL filter with notch filter AD, represented in the form of block diagram.

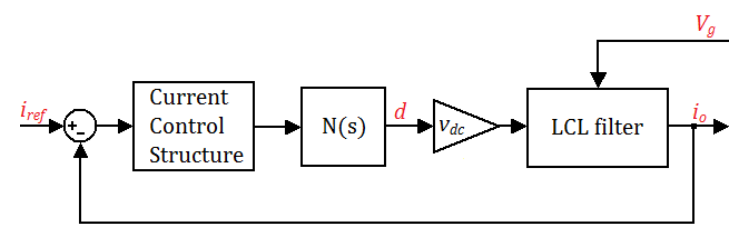

Source: The authors. 
The generic transfer function of a notch filter is given by equation (18), where $\zeta_{n z}$ and $\zeta_{n p}$ are the damping factor for the zeros and poles, respectively, and $\omega_{n f}$ is the filter tuning frequency. The factor $n$ refers to the number of sections inserted

$$
N(s)=\left(\frac{s^{2}+2 \zeta_{n z} \omega_{n f} s+\omega_{n f}^{2}}{s^{2}+2 \zeta_{n p} \omega_{n f} s+\omega_{n f}^{2}}\right)^{n}
$$

This strategy of AD, depicted in Figure 14, aims to compensate the LCL filter resonance by canceling it with the anti-resonance of the notch filter, therefore, the notch filter zeros must match the LCL filter poles responsible for the undesirable resonance.

As a result, generally, the settings $\zeta_{n z}=0$ and $\omega_{n f}=$ $\omega_{r}$ are preferred, achieving absolute cancellation at the resonance frequency (PEÑA-ALZOLA et al., 2013b).

However, the LCL filter resonance frequency value may suffer deviations as the grid equivalent inductance changes, rendering the notch filter AD ineffective. In order to provide some robustness to this method of $\mathrm{AD}$, Yao et al. (2017) proposes to allocate the notch filter frequency $\omega_{n f}$ in a position other than the resonant frequency $\omega_{r}$, taking advantage of inherent damping characteristics due to LCL filter passive elements intrinsic resistances.

Additionally, the effect of damping factor $\zeta_{n p}$ in the notch filter bandwidth influences the system sensibility to the grid inductance variation. With lower damping factor values the bandwidth becomes narrower, as showed in Figure 15, resulting in a more sensitive system, consequently, it is preferred broader bandwidth for the notch filter, as it helps improve the robustness to grid inductance variation (YAO et al., 2017).

Figure 15 - Bode diagram: notch filter response of different values of $\zeta_{n p}$.

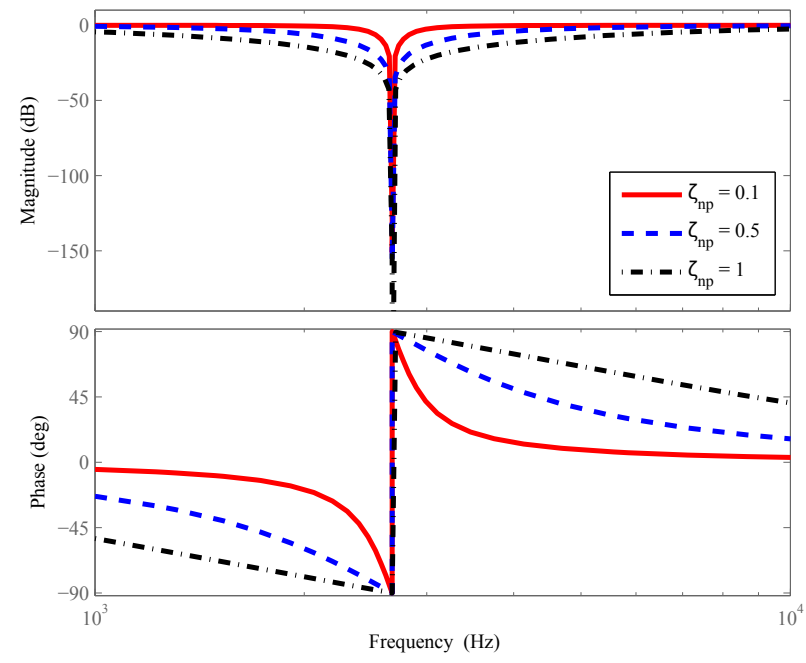

Source: The authors
The number of sections $n$ interfere in the phase lag and computational effort, Ciobotaru et al. (2016) suggests the use of $n=1$.

With regard to discretization, (YEPES et al., 2010) suggests the use of Tustin method with prewarping, as to maintain the frequency domain characteristics around the tuning point. The implementation of the notch filter in a DSP can be done by applying the z-domain form obtained by the discretization of equation (18) and apply it in the Direct Form II presented in Figure 3.

With these considerations, the frequency response for the notch filter $\mathrm{AD}$, designed for the system in Table 1 considering weak grid inductance, in comparison with an undamped LCL filter, is presented in Figure 16, made in MATLAB ${ }^{\circledR}$. As the simulation considers an ideal system, the notch filter is tuned to the resonance frequency, $\omega_{n f}=\omega_{r}$, the damping factors used are $\zeta_{n z}=0$ and $\zeta_{n p}=1$, with only one section.

Figure 16 - Bode diagram: frequency response comparison for filter without damping and with notch filter AD.
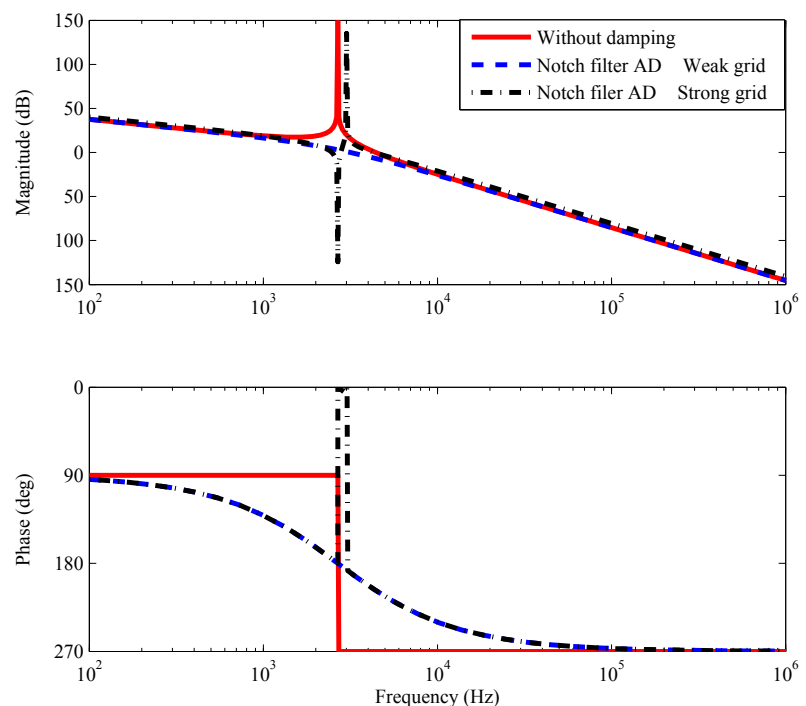

Source: The authors.

Figure 16 shows that the notch filter AD is capable of suppressing the resonant behavior without interfering in the LCL filter attenuation response, moreover, it does not dissipate energy as the PD options and has low implementation complexity. The main drawback of this strategy is the low robustness to grid inductance variation, being susceptible to lose the resonant suppression, even with the discussed design precautions, if the variation in resonance frequency is wide enough. Ciobotaru et al. (2016) proposes the use of adaptive notch filter, solving the grid equivalent inductance variation issue in dispense of more complexity and computational effort. 
The proportional gain design root locus plot for the system with notch filter AD is presented in Figure 17, with the same considerations as the series capacitor resistor PD. Adopting a value of $K_{p}=0.02$ ensures its stability.

Figure 17 - Root locus for $K_{p}$ design with notch filter AD.

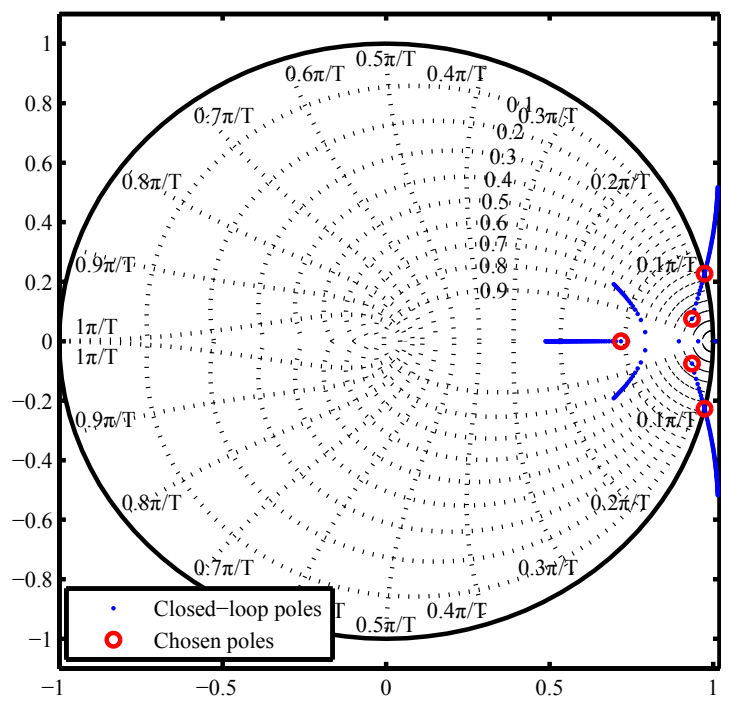

Source: The authors.

\section{Virtual resistor}

The virtual resistor $\mathrm{AD}$ method aims to emulate the application of PD techniques through an active approach, using the feedback of a chosen LCL filter signal, passing through a proportional gain or a digital filter (LIU et al., 2020), as illustrated in Figure 18, where $G_{a d}(s)$ is the transfer function of the digital filter necessary to emulate the desired PD response.

Figure 18 - VSI and LCL filter with virtual resistor AD, represented in the form of block diagram.

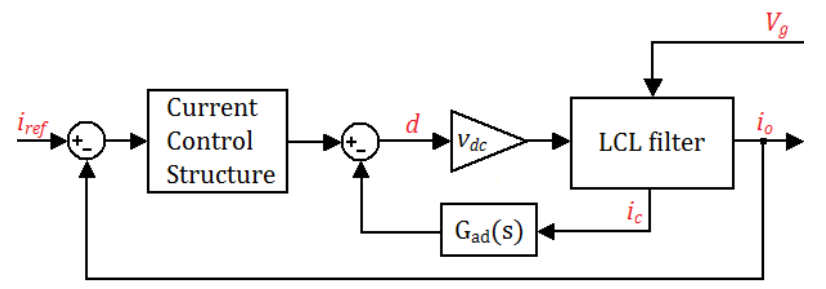

Source: The authors.

According to Liu et al. (2020) it is possible to emulate a variety of PD strategies using any of the current or voltage signals contained in the LCL filter, each with its own advantages and disadvantages, although, it is concluded that the capacitor current feedback emulating a resistor in parallel with the LCL filter capacitor, as depicted in Figure 19, has the best compromise in response and implementation, however it is necessary the use of additional sensors or signal estimators in order to implement this AD (LISTON et al., 2018).

Figure 19 - Equivalent circuit of the LCL filter with virtual resistor AD.

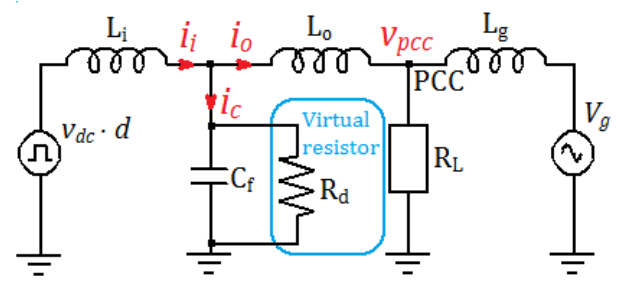

Source: The authors.

In order to obtain the equivalent circuit showed in Figure 19 through the control structure presented in Figure 18, Liu et al. (2020) demonstrates that the transfer function $G_{a d}(s)$ is actually defined as a proportional gain, as presented in equation (19),

$$
G_{a d}(s)=\frac{L_{i}}{C_{f} R_{d} v_{d c}} .
$$

By applying the capacitor current feedback with the gain presented in equation (19) the LCL filter behaves, regarding frequency response, as the circuit depicted in Figure 19. Therefore, by solving the circuit in Figure 19, considering $V_{g}=0$, a large load value, $d$ as input and $i_{o}$ as output signals, the transfer function for the filter with this kind of damping is presented in equation (20),

$$
G_{p c c f}(s)=\frac{i_{o}(s)}{d(s)}=\frac{\frac{v_{d c}}{L_{i} C_{f}\left(L_{o}+L_{g}\right)}}{s^{3}+\frac{1}{C_{f} R_{d}} s^{2}+\omega_{r}^{2} s}
$$

The absence of a zero in the equation (20) demonstrates that this type of damping does not affect the high frequency response of the filter, acting exclusively in the resonant behavior.

By comparing equations (20) and (8) the damping factor for this virtual resistor $\mathrm{AD}$ is obtained, given by equation (21),

$$
\zeta_{c c f}=\frac{1}{2 \omega_{r} C_{f} R_{d}} .
$$

Similarly to the PD, a good damping factor for the virtual resistor is $\zeta_{c c f}<<1$, and, together with root locus analysis, the damping factor can be used to design the virtual damping resistor $R_{d}$. 
For comparison purpose, the $R_{d}$ is designed in order to obtain the same damping factor as the series capacitor resistor PD technique. By applying $\zeta_{c c f}=0.17$ the resulting resistor is $R_{d}=45 \Omega$.

Figure 20 presents the frequency response comparison between an undamped filter and the designed virtual resistor $\mathrm{AD}$, obtained with $\mathrm{MATLAB}^{\circledR}$, showing that the virtual resistor AD successfully suppress the resonance without interfering in the high frequency attenuation.

Figure 20 - Bode diagram: frequency response comparison for filter without damping and with virtual resistor AD.

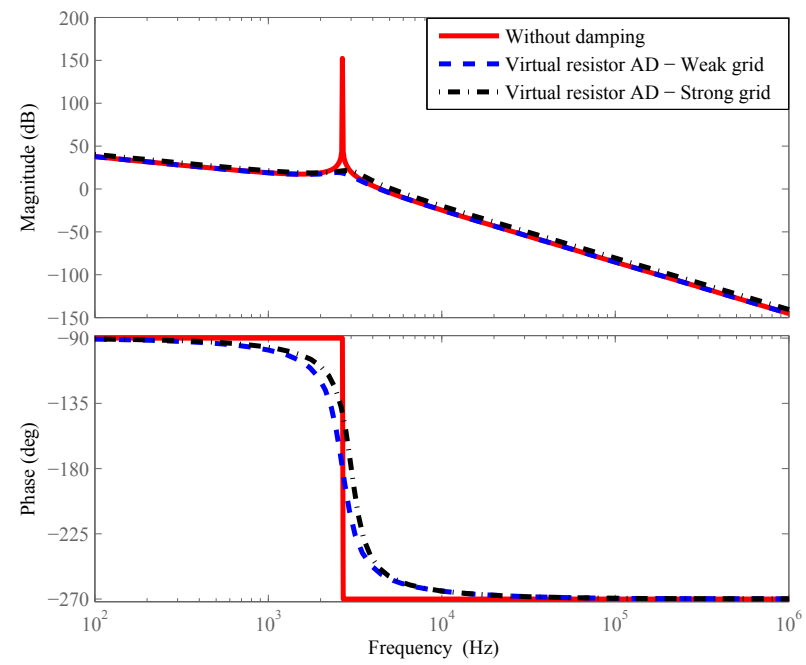

Source: The authors

Furthermore, this kind of AD also presents the advantage of being immune to grid equivalent inductance variation, however, the additional sensor or estimator necessary to achieve this kind of damping adds complexity to system.

In the work presented by Gomes, Cupertino and Pereira (2018), the virtual resistor AD is analyzed in two different types of feedback signal, capacitor current feedback (CCF) and capacitor voltage feedback (CVF). Although, in this present work, all the kinds of feedback emulating a resistor in parallel with the filters capacitor is treated as a similar LCL filter resultant response, as presented by Liu et al. (2020).

For the virtual resistor AD the proportional gain design is done through the root locus plot shown in Figure 21, in equal conditions to the previous damping strategies presented. It also presents an stable proportional gain of $K_{p}=0.02$ therefore it is the selected value.
Figure 21 - Root locus for $K_{p}$ design with virtual resistor AD.

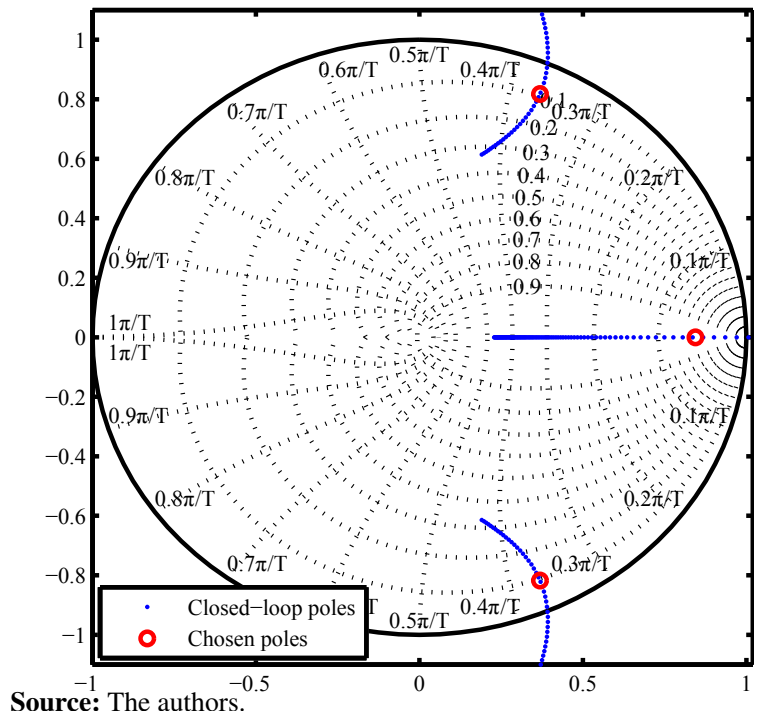

\section{Simulation results}

The grid-side current analysis of each damping technique discussed in the previous section is done by simulating the system depicted in Figure 1 in MATLAB ${ }^{\circledR}$ Simulink, using the parameters listed in Table 1. The control gains were defined by root locus, with a proportional gain $K_{p}=0.02$, which provides an stable response for all the studied damping cases. A resonant gain $K_{r}=40$ guarantees minimum steady-state error, and $K_{r h}=5$ ensures harmonic rejection for the third and fifth order components.

The grid condition simulates a distorted voltage with the third and fifth harmonics. The equivalent grid inductance and local load connected in the PCC is also considered.

The current reference values are $0.5 \mathrm{~A}$, of peak, from 0.1 seconds until 0.4 seconds, this condition is used for the harmonic content analysis. At the mark of 0.4 seconds an step is introduced leading the current to $1 \mathrm{~A}$ of peak.

Figure 22 shows the grid-side current result for all the damping strategies studied in this paper, beginning with the response in time for the undamped filter, and respectively: Series capacitor resistor $\mathrm{PD}$, parallel inductor resistor PD, complex PD, notch filter $\mathrm{AD}$ and, finally, virtual resistor $\mathrm{AD}$.

From Figure 22 it is possible to observe that, for the simulated system without intrinsic resistances, the undamped filter reaches instability. In the situations where some kind of damping is applied the system response are similar to each other, presenting a stable and visually undistorted grid-side current. 
Figure 22 - Grid-side current for each of the damping techniques, in equal condition, from Undamped filter case to Virtual Resistor AD, as noted.

(a) Undamped filter

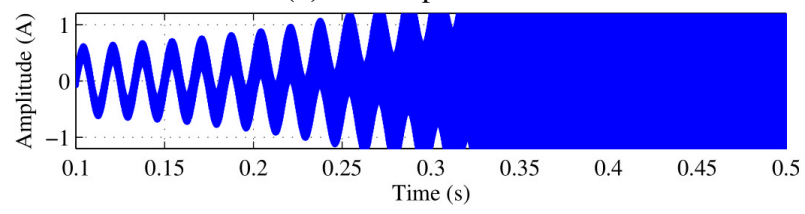

(b) Series capacitor resistor PD

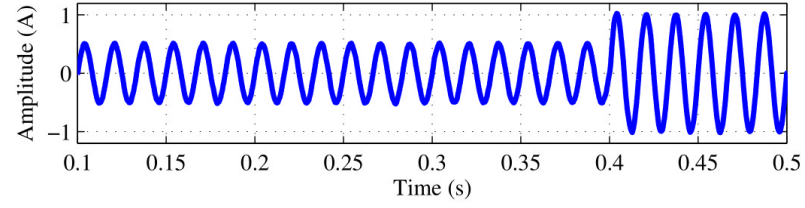

(c) Parallel inductor resistor PD

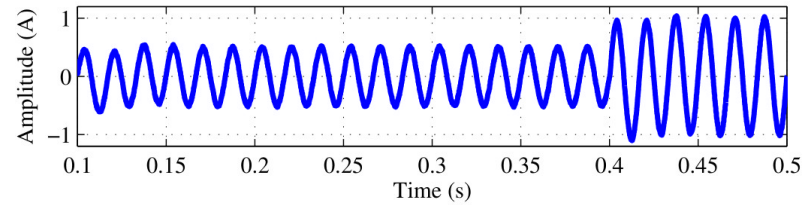

(d) Complex PD

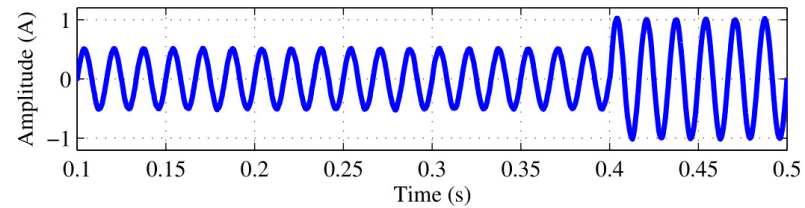

(e) Notch filter AD

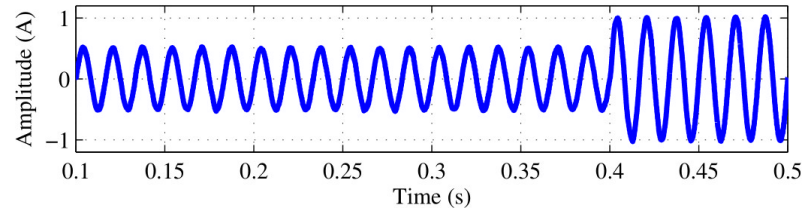

(f) Virtual resistor $\mathrm{AD}$

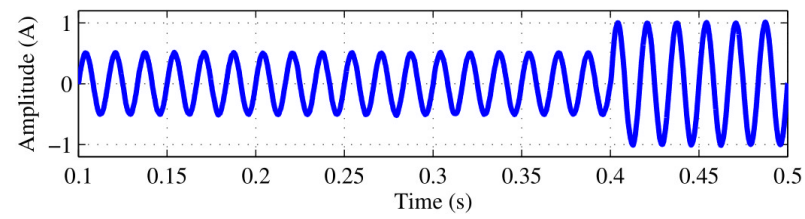

Source: The authors.

The response for the current reference step is also similar between the damping strategies, presenting an equally fast response.

To further analyze the grid-side current provided by each damping scheme, the harmonic content of the waveforms presented by Figure 22 is showed in Figure 23.

From Figure 23(a), the harmonic content of the gridside current of the undamped filter shows a prevalence of the resonant frequency, around $2600 \mathrm{~Hz}$, with amplitude above $100 \%$ of the fundamental component.
Figure 23 - Harmonic content for each of the damping techniques, in equal condition, from Undamped filter case to Virtual Resistor AD, as noted.

(a) Undamped Filter

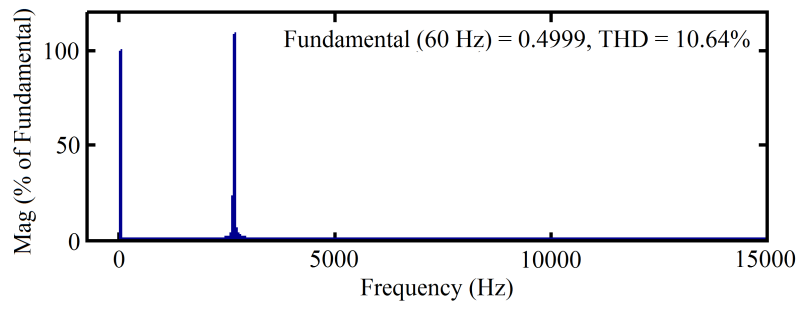

(b) Series Capacitor Resistor PD

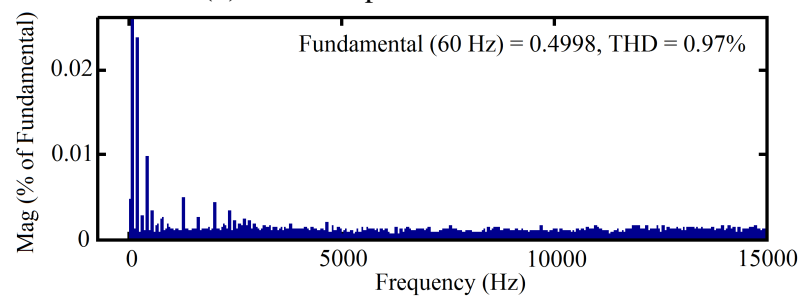

(c) Parallel Inductor Resistor PD

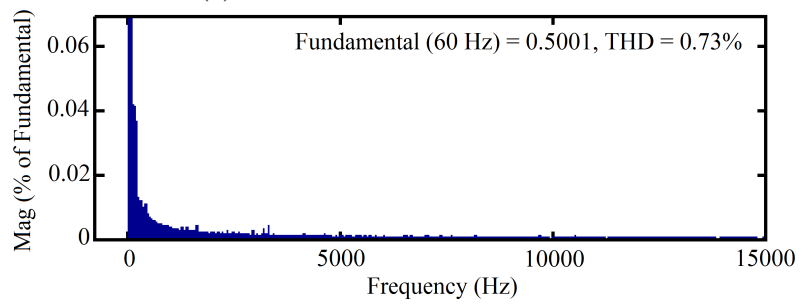

(d) Complex PD

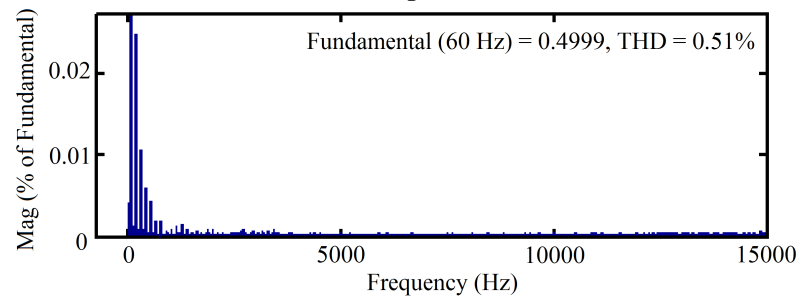

(e) Notch Filter AD

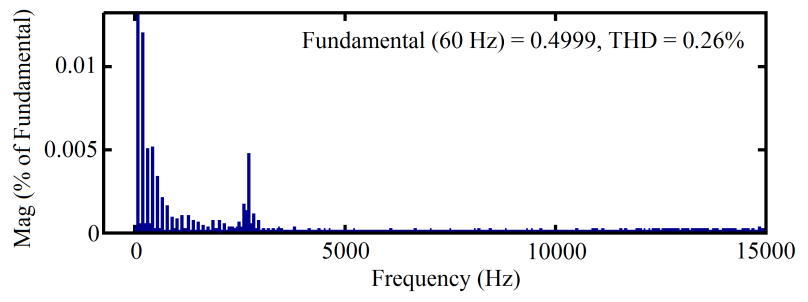

(f) Virtual Resistor AD

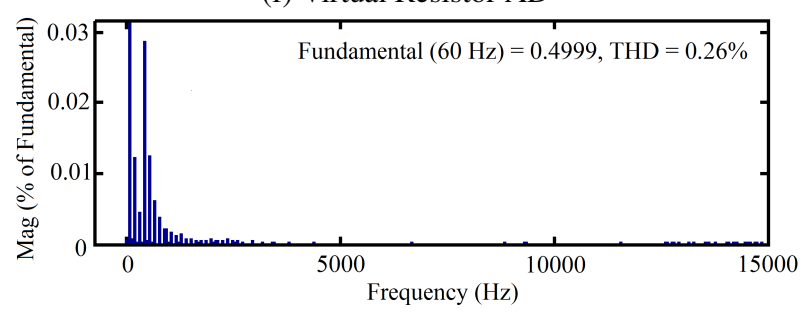

Source: The authors. 
The series capacitor resistor PD method, Figure 23(b), presents the worst THD, at $0.98 \%$, in comparison with the other damped responses, as expected by Figure 6.

The parallel inductor resistor PD, Figure 23(c), presents a better THD, at $0.73 \%$, however, as showed in Figure 9, it depends on the equivalent grid inductance to provide a better attenuation than the series capacitor resistor PD alternative.

The complex PD, Figure 23(d), presents the best THD of the PD schemes, with $0.58 \%$, this result associated with the lower power dissipation makes this type of PD purposive, although it is slightly more complex in implementation.

For the AD strategies, both presented equal THD value, at $0.26 \%$, below the mark showed by the PD methods, with the notch filter AD, Figure 23(e), presenting an spike in the resonant frequency value, while the virtual resistor AD, Figure 23(f), showed higher magnitude in the lower harmonic region.

The power quality standard IEEE 1547 (IEEE..., 2018) limits the current distortion to $5 \%$. With restrictions to individual ranges of harmonic content, for example, the individual odd harmonics below the eleventh order must be lower than $4 \%$ of the fundamental, as for odd harmonics above the order of 35 its magnitude must be lower than $0.3 \%$ of the fundamental value. Those limitations are met by all the presented damping schemes in the simulated environment.

However, the simulated system considers only the third and fifth harmonics to be present in the grid voltage, harmonic values on which the $\mathrm{HC}$ control actuates, therefore, the harmonic content comes mostly from the switching, resulting in THD below $1 \%$ for all the presented damping strategies.

Even though, it is possible to notice that each damping technique interferes differently in the filter response, where AD presents an slight improvement, not only in efficiency, but also in attenuation capabilities. As for PD schemes the presented complex method shows the better result.

\section{Conclusions}

The LCL filter provide a better attenuation at the cost of resonance that can lead to distortion in the injected current, and even instability in some circumstances, for this reason, efficient damping techniques prove necessary.

The series capacitor resistor PD is simple and can provide a reliable damping, however, it presents elevated power losses and affects negatively the LCL filter frequency response, as showed by mathematical analysis and simulation results.

By placing the resistor in parallel with grid-side inductor, mathematical modeling and simulation results shows that the LCL filter frequency response is improved in situations where there is equivalent grid inductance. It is also simple in implementation and promotes resonance suppression. Although, this technique has power losses and reduced robustness as drawbacks.

The split capacitor complex PD improves robustness to parameters variation and presents a similar attenuation in higher frequencies as the undamped LCL filter, and it also improves efficiency. Based on mathematical model and simulation results, this PD method proves to be the best alternative between the studied PD, although it presents more complexity.

The AD damping alternatives solves the power losses and reduced high frequency attenuation, introduced by PD. With the notch filter being simpler in implementation, needing only a second order filter in series with current control, while the virtual resistor needs additional measurements or signal estimation. However, by putting parameter variation robustness as the main concern, the virtual resistor $\mathrm{AD}$ is the best option between the two presented cases, as the notch filter is susceptible to lose its damping capability if the grid inductance suffers a wide enough variation, while the virtual resistor AD can endure a wider parameter range.

\section{Acknowledgments}

The authors wish to thank CAPES for the financial support.

\section{References}

BALASUBRAMANIAN, A. K.; JOHN, V. Analysis and design of split-capacitor resistive inductive passive damping for LCL filters in grid-connected inverters. IET Power Electron, [s. 1.], v. 6, p. 1822-1832, 2013. DOI: 10.1049/ietpel.2012.0679.

BARBOSA, A. U.; ALMEIDA, B. R.; GUIMARÃES, J. S.; OLIVEIRA, D. S. Distributed generation system using renewable energy sources and a new converter topology. In: IEEE INTERNATIONAL CONFERENCE ON INDUSTRY APPLICATIONS -INDUSCON, 12., 2016, Curitiba. Proceedings [... ]. Curitiba: IEEE, 2016. p. 1-6. DOI: 10.1109/INDUSCON.2016.7874583. 
BASSO, C. P. Transfer Functions. In: BASSO, C. P. (ed.). Linear circuit transfer functions: an introduction to fast analytical techniques. [New York]: John Wiley \& Sons, 2016. p. 41-115. DOI: 10.1002/9781119236344.ch02.

BERES, R. N.; WANG, X.; BLAABJERG, F.; LISERRE, M.; BAK, C. L. Optimal design of high-order passivedamped filters for grid-connected applications. IEEE Transactions on Power Electronics, New York, v. 31, n. 3, p. 2083-2098, 2016. DOI: 10.1109/TPEL.2015.2441299.

CALZO, G. L.; LEGA, M.; LIDOZZI, A.; SOLERO, L.; CRESCINBINI, F. Single-phase three-level transformerless inverter for residential distributed generation. In: INTERNATIONAL ENERGY CONFERENCE AND EXHIBITION, 2012, Florence. Proceedings [...]. Florence: IEEE, 2012. p. 7-12. DOI: 10.1109/EnergyCon.2012.6348260.

CHA, H.; VU, T. Comparative analysis of low-pass output filter for single-phase grid-connected photovoltaic inverter. In: ANNUAL IEEE APPLIED POWER ELECTRONICS CONFERENCE AND EXPOSITION - APEC, 2010, Palm Springs. Conference [... ].Palm Springs: IEEE, 2010. p. 1659-1665. DOI: 10.1109/APEC.2010.5433454.

CHANNEGOWDA, P.; JOHN V. Filter optimization for grid interactive voltage source inverters, IEEE Transactions on Industrial Electronics, New York, v. 57, n. 12, p. 4106- 4114, 2010. DOI: 10.1109/TIE.2010.2042421.

CIOBOTARU, M.; ROSSÉ, A.; BEDE, L.; KARANAYIL, B.; AGELIDIS, V. G. Adaptive Notch filter based active damping for power converters using LCL filters. INTERNATIONAL SYMPOSIUM ON POWER ELECTRONICS FOR DISTRIBUTED GENERATION SYSTEMS -PEDG, 7., 2016, Vancouver. Symposium [... ].Vancouver: IEEE, 2016. p. 1-7. DOI: 10.1109/PEDG.2016.7527081.

DANNEHL, J.; LISERRE, M.; FUCHS, F. W. Filter based active damping of voltage source converters with lcl filter. IEEE Transactions on Industrial Electronics, New York, v. 58, n. 8, p. 3623-3633, 2011. DOI: 10.1109/TIE.2010.2081952.

GOMES, C. C.; CUPERTINO, A. F.; PEREIRA, H. A. Damping techniques for grid-connected voltage source converters based on LCL filter: An overview, Renewable and Sustainable Energy Reviews, v. 81, p. 116-135, 2018. ISSN 1364-0321, DOI: 10.1016/j.rser.2017.07.050.
GUO, X.; WU, W.; GU, H. Modeling and simulation of direct output current control for LCL-interfaced gridconnected inverters with parallel passive damping, Simulation Modeling Practice and Theory, v. 18, p. 946-956, 2010. DOI: 10.1016/j.simpat.2010.02.010.

IEEE Standard for Interconnection and Interoperability of Distributed Energy Resources with Associated Electric Power Systems Interfaces. IEEE, New York, p. 1-138, 2018. DOI: 10.1109/IEEESTD.2018.8332112.

KANG, Y.; DAI. K.; DUAN. K.; KANG, Y. Application of a C-Type filter based LCFL output filter to shunt active power filters. Journal of Power Electronics, Stevenson Ranch, v. 13, n. 6, p. 1058-1069, 2013. DOI: 10.6113/JPE.2013.13.6.1058.

KAURANIEMI, J.; LAAKSO, T. I.; HARTIMO, I.; OVASKA, S. J. Delta operator realizations of directform IIR filters. IEEE Transactions on Circuits and Systems II: analog and digital signal processing, Piscataway, v. 45, n. 1, p. 41-52, 1998. DOI: 10.1109/82.659455.

KRAEMER, R. A. S.; CARATI, E. G.; COSTA, J. P.; CARDOSO, R.; STEIN, C. M. O. Robust design of control structure for three-phase grid-tied inverters. In: IEEE INTERNATIONAL CONFERENCE ON INDUSTRY APPLICATIONS -INDUSCON, 13., 2018, São Paulo. Proceedings [...]. São Paulo: IEEE, 2018. p. 636-643. DOI: 10.1109/INDUSCON.2018.8627068.

LISERRE, M.; BLAABJERG, F.; HANSEN, S. Design and control of an LCL-filter-based three-phase active rectifier, IEEE Transactions on Industry Applications, vol. 41, no. 5, pp. 1281-1291, Sept.-Oct. 2005, DOI: 10.1109/TIA.2005.853373.

LISTON, R. A.; CARATI; E. G.; CARDOSO, R.; COSTA, J. P.; STEIN, C. M. O. A Robust design of active damping with a current estimator for singlephase grid-tied inverters. IEEE Transactions on Industry Applications, New York, v. 54, n. 5, p. 4672-4681, 2018. DOI: 10.1109/TIA.2018.2838074.

LIU, T., LIU, J., LIU, Z., LIU, Z. A Study of virtual resistor-based active damping alternatives for lcl resonance in grid-connected voltage source inverters. IEEE Transactions on Power Electronics, New York, v. 35, n. 1, p. 247- 262, 2020. DOI: 10.1109/TPEL.2019.2911163. 
PARKER, S. G.; MCGRATH, B. P.; HOLMES, D. G. Regions of active damping control for LCL filters. IEEE Transactions on Industry Applications, New York, v. 50, p. 424 - 432, 2014. DOI: 10.1109/TIA.2013.2266892.

PEÑA-ALZOLA, R.; LISERRE, M; BLAABJERG, F.; SEBASTIÁN, R.; DANNEHL, J.; FUCHS, F. W. Analysis of the passive damping losses in LCL-filter-based grid converters. IEEE Transactions on Power Electronics, New York, v. 28, n. 6, p. 2642-2646, 2013a. DOI: 10.1109/TPEL.2012.2222931.

PEÑA-ALZOLA, R.; LISERRE, M.; BLAABJERG, F.; ORDONEZ, M.; YANG, Y. LCL-filter design for robust active damping in grid connected converters. IEEE Transactions on Industrial Informatics, Piscataway, v. 10, p. 2192 - 2203, 2014. DOI: 10.1109/TII.2014.2361604.

PEÑA-ALZOLA, R.; LISERRE, M.; BLAABJERG, F.; KEREKES, T. Self-commissioning notch filter for active damping in three phase LCL-filter based grid converters. In: CONFERENCE ON POWER ELECTRONICS AND APPLICATIONS - EPE, 15., 2013b, Lille. Proceedings [...]. Lille: IEEE, 2013. p. 1-9. DOI: 10.1109/EPE.2013.6631962.

ROCKHILL, A. A.; LISERRE, M.; TEODORESCU, R.; RODRIGUEZ, P. Grid-Filter design for a multimegawatt medium-voltage voltage-source inverter. IEEE transactions on industrial electronics, New York, v. 58, n. 4, p. $1205-1217,2011$. DOI: 10.1109/TIE.2010.2087293.

WANG, T. C. Y.; YE, Z.; SINHA, G.; YUAN, X. Output filter design for a grid-interconnected three-phase inverter. In: ANNUAL CONFERENCE ON POWER ELECTRONICS SPECIALIST, 34., 2003, Acapulco. Proceedings [...]. Acapulco: IEEE, 2003. p. 779-784. DOI: 10.1109/PESC.2003.1218154.

XIN, Z.; LOH, P. C.; WANG, X.; BLAABJERG, F.; TANG, Y. Highly Accurate Derivatives for LCLfiltered grid converter with capacitor voltage active damping. IEEE Transactions on Power Electronics, New York, v. 31, n. 5, p. 3612-3625, 2016. DOI: 10.1109/TPEL.2015.2467313.
YADAV, A.; SRIVASTAVA, L. Optimal placement of distributed generation: an overview and key issues. In: INTERNATIONAL CONFERENCE ON POWER SIGNALS CONTROL AND COMPUTATIONS - EPSCICON, 2014,Thrissur. Proceedings [...]. Thrissur: IEEE, 2014. p. 1-6. DOI: 10.1109/EPSCICON.2014.6887517. 2014

YAGNIK, U. P.; SOLANKI, M. D. Comparison of L, LC and LCL filter for grid connected converter, 2017 International Conference on Trends in Electronics and Informatics (ICEI), 2017, pp. 455-458, DOI: 10.1109/ICOEI.2017.8300968.

YAO, W.; YANG, Y.; ZHANG, X.; BLAABJERG, F.; $\mathrm{LOH}, \mathrm{P}$. C. Design and analysis of robust active damping for lcl filters using digital notch filters. IEEE Transactions on Power Electronics, New York, v. 32, n. 3, p. 2360-2375, 2017. DOI: 10.1109/TPEL.2016.2565598.

YEPES, A. G.; FREIJEDO, F. D.; DOVAL-GANDOY, J.; LÓPEZ, Ó.; MALVAR, J.; FERNANDEZ-COMESAÑA, P. Effects of discretization methods on the performance of resonant controllers. IEEE Transactions on Power Electronics, New York, v. 25, n. 7, p. 1692-1712, 2010. DOI: 10.1109/TPEL.2010.2041256.

YUAN, X.; MERK, W.; STEMMLER, H.; ALLMELING, J.; Stationary-frame generalized integrators for current control of active power filters with zero steady-state error for current harmonics of concern under unbalanced and distorted operating conditions. IEEE Transactions on Industry Applications, New York, v. 38, n. 2, p. 523-532, 2002. DOI: $10.1109 / 28.993175$. 